\title{
FOGO DE 51 \\ UMA NARRATIVA DA DOR DO POVO PATAXÓ DA BAHIA
} Vera Lúcia da Silva é professora da Secretaria de Educação da Bahia, mestranda do Programa de Literatura, cultura e
contemporaneidade da PUC Rio e bolsista CNPQ.
Email: vsilva.lucia@hotmail.com

\section{Resumo}

O presente artigo abre uma reflexão sobre a necessidade de narrar a ação mais violenta do século XX contra o povo Pataxó, o Fogo de 51. Será pensado ainda o potencial da narrativa para a educação.

\begin{abstract}
This article opens a reflection on the need to narrate the most violent attack against the Pataxó people in the $20^{\text {th }}$ century, the Fire 51. The narrative potential for education will also be taken into consideration.
\end{abstract}

Havia um povo nesta terra. No início eram poucos, depois Antes, era muita gente. Agora somos poucos. Com o passar do tempo vieram outras pessoas. se tornaram muitos. E então, o que era muito foi desaparecendo aos poucos e o que era pouco foi ficando com tudo.

Jovem Pataxó em Cumuruxatiba em encontro da Frente de Resistência e Luta Pataxó

\section{1) Introdução}

É possível que a natureza deste trabalho exija uma justificativa preliminar acerca do meu envolvimento com o objeto sobre o qual aqui se refletirá. $O$ fato é que cheguei em fevereiro de 2011 ao belo distrito de Prado, Cumuruxatiba, para uma jornada pedagógica específica para as escolas indígenas de Corumbauzinho, Bom Jesus e Kijêtxawê Zabelê, no intuito de apresentar os projetos de música, arte literária e artes visuais, coordenados pela Secretaria de Educação do Estado da Bahia. Cheguei com a ideia de índio implantada em meu imaginário pelos romances de Alencar, esperava encontrar Iracemas e Peris, nunca Catherines e Uilians (apesar dos nomes indígenas não-oficiais). Tudo o que se seguiu foi surpresa, desapontamento, encantamento, perguntas e muita vontade de voltar, saber.

Após meses de convívio e leituras sobre o povo atendido pelas escolas já citadas, os Pataxó ${ }^{i}$ do extremo sul da Bahia, continuo encantada, mas agora envolvida por um tipo de encantamento menos calcado na beleza dos seus rituais, da sua música, das suas histórias ancestrais, das suas pinturas impregnadas de sentidos obscuros para mim e da sua língua indecifrável - arame farpado às vezes propositadamente posto entre mim e eles. Tenho cada vez mais perguntas, e as faço a eles. Respondem a algumas, mas a 
outras não sabem responder; então, devolvem em forma de questionamento angustiado, pungente. Convidam-me a voltar, a pensar junto.

Para pensar as questões propostas por eles - o funcionamento das práticas de leitura realizadas no chão de suas escolas - é preciso, sem dúvida, situar historicamente, mesmo que de forma abreviada, o contexto no qual se situará a reflexão. Também aqui, para a reflexão ora pretendida em torno da principal narrativa da dor pataxó no século $\mathrm{XX}$, talvez a mais recente e violenta tentativa branca de dispersar esse povo de seu território imemorial, é preciso convocar um pouco da história.

\section{2) Breve descrição dos Pataxó da Barra do Cahy}

No extremo sul da Bahia vivem os Pataxó, que, antropologicamente pertencem ao tronco Macro-Jê, falam cotidianamente a língua portuguesa, embora o patxohã - a linguagem do guerreiro, depois de ser considerada extinta por alguns autores, venha sendo revitalizada com a valorosa colaboração de Zabelê, dona Luciana Ferreira, anciã e líder Pataxó, filha da Aldeia Barra Velha, mas hoje moradora da Tibá. Nesse processo também colaboram alguns índios que vêm estudando o assunto à luz da sociolinguística e da gramática, assim como os professores de cultura que desempenham um importante papel na sistematização e compartilhamento dos saberes tradicionais desse povo.

Esse grupo étnico está distribuído em vinte e três aldeias, duas das quais situadas em Minas Gerais, nos municípios de Carmésia, desde o início da década de 80, e Araçuaí, desde 2005. As demais aldeias estão distribuídas na região do extremo sul baiano, sendo que doze delas no município de Prado, entre Cumuruxatiba e a foz do rio Corumbau: Tibá; Pequi; Cahy; Dois Irmãos; Alegria Nova; Gurita; Monte Dourado; Corumbauzinho; Tawá; Craveiros; Aldeia Nova e Águas Belas, formadas por um contigente já superior a um mil e trezentos indivíduos. Informo que essa conformação está longe de ser estável, a expectativa é de que novas aldeias surjam sempre e algumas até deixem de existir.

É preciso evidenciar que boa parte das aldeias está situada em áreas fortemente marcadas por polêmicas com relação à demarcação do território imemorial indígena, já prevista pelo artigo 231, da Lei $n^{\circ}$ 6001, de 1973. Parte dos problemas é em decorrência da sobreposição de dois patrimônios mundiais da humanidade às terras pataxó: o Parque Nacional do Descobrimento e o Parque Nacional de Monte Pascoal, além da Reserva Extrativista Marinha Corumbau-Cumuruxatiba. É desejo dos Pataxó que, com a demarcação, eles mesmos possam garantir a preservação/conservação dessas importantes reservas biológicas e culturais, hoje sob a responsabilidade do Instituto Chico Mendes - ICM Bio.

O antropólogo Mércio Gomes (2008) no "Blog do Mércio: índios, antropologia e cultura", sob sua responsabilidade, afirma que será "dificílimo" demarcar a área pretendida pelos indígenas e inventariada pela antropóloga da Universidade Federal da 
Bahia, Maria do Rosário Gonçalves de Carvalho. A área antes pleiteada a partir do laudo da também antropóloga Leila Sotto Maior, que era de vinte e oito mil hectares, passa a ser de cento e vinte mil hectares. Gomes (2008) sentencia que:

Não há por que os índios se dividirem e voltarem a achar que o canto de sereia, a ilusão de demarcar uma área de 120.000 hectares, é possível. Isto é o que um outro antropólogo vendedor de ilusões convenceu a FUNAI a fazer no Mato Grosso do Sul, cujas conseqüências os índios estão sofrendo, pois a própria FUNAI vai ser forçada a recuar, deixando todos em frustração incomensurável (Gomes, 2008).

Em 1815, o Príncipe Maximiliano de Wied-Neuwied (apud Batista 2011, p.11) descreve os Pataxó da área já citada (e compreendida por muitos como excessivamente extensa face aos interesses econômicos em jogo) como "os selvagens mais desconfiados e reservados entre todos". Talvez por serem mesmo arredios é que sobreviveram a tantos e diversos ataques etnocidas contra sua subjetividade individual e coletiva. Já para a pesquisadora Maria Geovanda Batista (2011) foram a habilidade, a flexibilidade e a abertura deles para estabelecer relações interculturais com as sociedades envolventes, que garantiram sua sobrevivência, e que, não fosse essa maestria, hoje já teriam sido eliminados, reduzidos e ou incorporados por outras etnias. Na aparente contradição entre as caracterizações mencionadas, é possível entender que os Pataxó estabeleciam as relações necessárias para sua sobrevivência como povo indígena, porém sem permitir uma aproximação que fosse danosa no sentido de provocar a dissolução irreversível de seus modos próprios de vida.

Ainda segundo Wied-Neuwied (apud Batista 2011, p.11), na Cumuruxatiba de 1815, havia a fazenda Caledônia do inglês Charles Fraser, que utilizava mão de obra escravizada de trinta negros africanos e de outros tantos índios "praieiros". O segundo nessa linha de sucessão foi o alemão John Gordon, primeiro explorador de areia monazítica da região. Em 1928, o brasileiro José Rodrigues passou a administrar a exploração da areia e mais a da madeira, sabendo se valer também da boa relação existente com os "caboclos", habilidade estendida a seus parentes proprietários de negócios e fazendas improdutivas espalhadas por toda a Barra do Cahy, Ponta do Moreira e Imbassaúba.

Assim, a presença de estrangeiros e não-índios no território imemorial Pataxó limita-se a interesses de ordem econômica e, desde que os nativos não se tornassem perigosos, dispostos ao conflito, permitia-se que continuassem à frente na condução dos ritos e práticas religiosas na igreja de São Sebastião, hoje Santo Antônio, o que tornava possível a transculturalidade das vivências culturais, espirituais e, dessa maneira, a própria sobrevivência do ser-índio. Além do domínio no panorama religioso, os Pataxó puderam exercer cargos no poder local nas áreas de segurança e educação, por várias décadas.

Esse período foi rompido violentamente pelo processo de criação do Parque Nacional de Monte Pascoal, em 1943 (oficializado em 1961), sobreposto ao território Pataxó, sem considerar as evidências materiais e históricas (casas, plantações, 
cemitérios, sambaquis) que apontam para seus verdadeiros proprietários. Ainda nesse mesmo contexto, já fora da era Rodrigues, ocorreu um fato ainda vivo e latente na memória Pataxó, o Fogo de 51, também conhecido como a Revolta de Barra Velha, quando policiais militares de Prado e Porto Seguro atacaram violentamente a aldeia mãe, Barra Velha, sob a alegação que havia revoltosos saqueando armazéns de regionais em Corumbau. O resultado foi a morte de indígenas e o início de uma invasão cada vez mais violenta em seus métodos.

Em 1998, na vila indígena de Cumuruxatiba, cada vez mais multicultural, os Pataxó se encontravam desarticulados politicamente e cada vez mais, como estratégia de sobrevivência, mesmo, diluídos no universo não-índio, trabalhando como assalariados, em especial na área de turismo, afastados da centralidade dos eventos culturais e religiosos e tendo seus filhos matriculados em escolas de currículo "branqueado". Enfim, passaram a viver, sem exagero, na fronteira da exclusão.

Porém, por ocasião dos 500 anos da invasão portuguesa ao Brasil, movimentos indígenas, indigenistas, negros e populares se articularam em um movimento denominado "Brasil Outros 500", como contraponto às comemorações oficiais organizados pelos Governos. Vale ressaltar que em 1999 é criado o Parque Nacional do Descobrimento, também sobreposto ao território imemorial Pataxó, e em 2000, este é declarado pela UNESCO patrimônio da humanidade, isso em um contexto em que os índios se organizam para a luta de permanecer, de continuar sendo. Esse contexto aparece claramente no canto entoado durante o $a w e^{\mathrm{ii}}$ :

Diga ao povo que avance

Diga ao povo que avançaremos

Para defender nossa nação, vamos todos dar as mãos

Diga ao povo que avance

Diga ao povo que avançaremos

Para defender nossa nação, vamos todos dar as mãos

Nós somos índios Pataxó

Somos da nova geração

Nossos antepassados morreram para defender a nossa nação

O senhor o presidente libera a nossa terra

A nossa aldeia está sofrendo, nós precisamos da nossa terra

Diga ao povo que avance

Diga ao povo que avançaremos

Para defender nossa nação, vamos todos dar as mãos

Nós somos índios Pataxó

Somos da nova geração

Nossos antepassados morreram para defender a nossa nação

O senhor o presidente libera a nossa terra

A nossa aldeia está sofrendo, nós precisamos da nossa terra

(Esperança Luminosa, 2005, p.31)

Passou-se mais de uma década e importantes passos foram dados na luta pataxó pela retomada da terra, que vai muito além de espaço físico, trata-se da retomada de si, do corpus coletivo, da indianeidade em um terreno marcado historicamente pela 
multiculturalidade no qual os Pataxó têm aprendido, a bem de sua sobrevivência, desde os primeiros contatos, a assumir uma interculturalidade que não os enfraquece como comunidade e etnia. Para Batista (2011), a interculturalidade pode ser feita a serviço de muitos interesses: o de fortalecer, revitalizar as culturas e identidades, como também de destruí-las, enfraquecê-las ou transformá-las à revelia do consentimento social ou grupal.

\section{3) Testemunhas do Fogo de 51}

Eu morava na aldeia da Barra Velha, tive minha família toda por lá, depois que teve uma revolta na barra velha eu saí de lá e não quis ir mais para lá, agora nós estamos morando em Cumuruxatiba.

Eu vou contar muita coisa sobre a revolta, a polícia pegou o meu pai, pisou em cima dele, eu estava vendo tudo, levou a minha mãe e amarrou perto de meu pai para eles mostrarem onde é que estavam os índios que correram. Pegaram um índio e o fizeram de camundu (cavalo), botaram uma cangalha e um caçoá em cima do velho para mostrar onde é que estavam os índios, mas como é que eles iam mostrar sem saber.

Todos os índios correram, foram embora para os matos, e ficaram só os mais velhos que não podiam correr e eles pegaram.

É por isso que eu não tenho coração de ir morar na Barra Velha, eu não, quando chego lá só me lembro disso, do que fizeram com o meu velho, aí não da vontade mais de ficar lá, por isso vim embora para Cumuruxatiba. Fiquei morando neste lugar até hoje.

Aqui tinha muito índio, todo mundo tinha amizade comigo, aqui também era uma aldeia, e eu disse:

_ Agora aqui é uma aldeia, então fico aqui, e para lá não vou mais, lá não tem meu pai, não tem minha mãe, só tenho um irmão, mas não me dá vontade de ir mais para lá (Relato de Zabelê, em Rodrigues, Silva \& Soares, 2005, p.10).

O relato acima está registrado em um pequeno caderno batizado de Esperança Luminosa (compareceu em citação anterior), organizada pelo Conselho Indigenista Missionário - Cimi, organização não governamental interessada em colher narrativas indígenas, entre outros assuntos. Porém, parece-me que a iniciativa, apesar de válida, na referida publicação mostrou-se pontual e desligada de qualquer atividade de pesquisa sobre o povo em questão. A circulação também é outro ponto a ser questionado, vez que a tiragem fica restrita a atender de forma insuficiente as aldeias da Barra do Cahy, de forma que as histórias dessa comunidade fronteiriça continuam sem circulação, inexistentes em espaços não indígenas, mesmo quando a distância geográfica dos indígenas e não-indígenas é ínfima ou nenhuma e a convivência é um imperativo.

Também sobre o Fogo de 51, encontrei em um site de assuntos indígenas (www.indiosonline.net), o relato de Edmundo Santos, membro da Comissão de Educadores Indígenas e militante da Frente de Resistência e Luta Pataxó - COEDIN, cujo nome indígena não aparece. O testemunho de Edmundo é de um jovem pataxó que testemunhou o massacre pelo contar de quem o experienciou, podemos dizer assim que se trata de uma testemunha da testemunha. Talvez por isso, encontro em sua narrativa mais detalhes: 
Mulheres estupradas, crianças amarradas, todos chicoteados e levados até a cidade vizinha de Caraíva, onde sofreram as vaias dos habitantes não índios. Índios foram arreados com rédeas de tiririca, planta urticante, e cavalgados pelos soldados. Outro teve que carregar um porco de quatro arrobas ao longo dos $7 \mathrm{~km}$ que separam a aldeia da povoação de Caraíva. Este massacre durou 30 (trinta) dias, até pegarem os dois ladrões e também um índio que fugiu com eles. Matando-os a tiros, enterraram os três na mesma sepultura, próximo ao Monte Pascoal. Hoje próximo à Aldeia Guaxuma (Santos, 2006).

Já no relato de dona Luciana Ferreira, Zabelê Pataxó (nome de pássaro miúdo e multicolorido), é possível perceber a reticência, a lacuna do que não pode ser dito senão pelo próprio não dizer (também uma forma de dizer) da qual nos fala Giorgio Agamben (2008) - ou seja, são os vazios de quem viu o horror executado. Ao ler o registro do testemunho de Zabelê, agora já mediado pela representante do CIMI que o retextualizou, é possível vê-la recuando, resistente frente à responsabilidade e a obrigação de contar. Mas, apesar do não querer voltar a Barra Velha - o lugar da dor, mesmo que seja num tempo e espaço outro, é ela mesma quem afirma, como que reiterando sua autoridade para narrar o Fogo, "eu estava vendo tudo". E conta.

Narra uma história que é de todos os Pataxó e de alguma forma também de todos aqueles desejosos e necessitados de saber da existência das margens dessa sociedade de mente ocidental, a partir de uma perspectiva individual: "a polícia pegou o meu pai, pisou em cima dele, eu estava vendo tudo, levou a minha mãe". Toda a narrativa segue nesse tom, dando conta apenas do que ela, ainda menina, pôde ver quando policiais das cidades de Porto Seguro e Itamaraju, sob o pretexto de estarem à caça de criminosos que teriam assaltado um comerciante do entorno, violentaram os moradores de Barra Velha das mais diversas formas e os expuseram a humilhações públicas execráveis. Ao cabo de trinta dias, essa força tarefa, que os Pataxó até hoje creem ter cumprido ordens do estado, consegue espoliar o território imemorial desse povo, dispersando-o para toda o extremo sul baiano, em especial, para Prado e Itamaraju.

Parece-me, lendo a precária narrativa de dona Zabelê, mulher-pássaro, que há muito a ser lido nos silêncios de seu texto, nos sons inauditos, em uma não-língua dentro do código conhecido. Para Agamben (2008, p. 48), "é sobre a natureza deste nãotestemunhado, sobre a não-língua que é preciso interrogar-se", compreender a potência de comunicação da experiência na própria impossibilidade/dificuldade do sobrevivente de testemunhá-la.

É interessante, mesmo sem poder alongar-me nessa discussão, dizer que esse testemunho é dado na língua do perpetrador, daquele mais uma vez invasor, que expulsa da terra ancestral. A língua cabralina, adjetivo tomado emprestado do discurso de Edmundo Santos, é aquela, no Fogo de 51, empunhada para promover o início de mais uma dispersão, a partir daí só intensificada pela a ação de fazendeiros, mineradoras, madeireiras, empresas de celulose e, por último, empresas de turismo. Em uma de suas participações no site já mencionado, Santos sugere que é preciso ver os invasores portugueses como aqueles que não apenas se apropriaram do território, mas também 
como os que, através da Igreja Católica, realizaram uma “invasão ideológica”. Chama à atenção para o fato de isso ter ocorrido e se consolidado através da língua da metrópole.

\section{4) Sobre a necessidade das narrativas da dor}

Desconfio que é preciso narrar a dor dos Pataxó do Prado, ainda que no código odiado, porém ainda utilizado como sua primeira língua. Elie Wiesel (1994, p.23), refletindo sobre sua própria necessidade de escrever sobre os horrores da Shoá, lança luz, talvez, sobre os motivos que justificariam uma escritura não apenas da violência de 51, mas de todas as outras, inclusas as mais sutis em seus meios. Wiesel escreve para não enlouquecer, para cumprir um dever, "através do silêncio". Como o autor, Zabelê, como sobrevivente e anciã - para o povo indígena o ancião é o narrador autorizado das histórias e práticas da comunidade, o guardador e professor de cultura - sabe que precisa contar a história, pois deixar de fazê-lo, seria trair a própria experiência.

É também Wiesel (1994, p.24) que fala sobre a necessidade de "forçar o homem a olhar". A partir dessa afirmativa, arrisco-me a pensar o registro e a circulação das narrativas da dor do povo indígena como dispositivos necessários para fomentar discussões em torno da constituição de nosso país, de nossa ideia de nação e de nós mesmos. Essa escritura forçaria um olhar de perto, talvez um comprometimento, não da ordem da compaixão ou da solidariedade, para Susan Sontag uma forma encontrada para desculpar a barbárie. Para ela:

Na medida em que sentimos solidariedade, sentimos não ser cúmplices daquilo que causou sofrimento. Nossa solidariedade proclama nossa inocência, assim como proclama nossa impotência. Nessa medida (a despeito de todas as nossas boas intenções), ela pode ser uma reação impertinente - senão imprópria. Pôr de parte a solidariedade que oferecemos aos outros, quando assediados por uma guerra ou por assassinatos políticos, a fim de refletirmos sobre o modo como os nossos privilégios se situam no mesmo mapa que o sofrimento deles e podem - de maneiras que talvez prefiramos não imaginar - estar associados a esse sofrimento, assim como a riqueza de alguns pode supor a privação para outros, é uma tarefa para a qual as imagens dolorosas e pungentes fornecem apenas uma centelha inicial (Sontag, 2003, p.86).

Ainda para pensar a necessidade de narrar o horror, trago aqui Maria Rita Kehl (2003, p.143) afirmando que "é preciso falar para tornar menos imperativo o desejo de praticar o mal". No entanto a própria autora acrescenta no mesmo artigo que não há como garantir que o mal não seja praticado, mas silenciá-lo seria paradoxalmente deixar-lhe espaço de voz e de ação. Permitir, por exemplo, que se discuta, em uma das maiores redes de televisão e comunicação do Brasilii, a questão da demarcação das terras indígenas no Prado, como se os índios fossem espoliadores de terrenos comprados, pagos e tão bem utilizados pela indústria do turismo e por fazendeiros produtores de alimentos, e que em mãos dos Pataxó, preguiçosos como todo o povo indígena, seriam inúteis e gradativamente empobrecidos, é uma das consequências desse 
silenciamento da história indígena na região. As populações do entorno e de boa parte do país ainda mantêm a visão preconceituosa fundada pela lógica homogeneizante e escravocrata do colonizador: terra em mãos de índio é um desperdício.

Outro ponto interessante para a nossa reflexão e que é abordado por Adorno (1995, p.107) é a supremacia do geral sobre o particular, em uma perspectiva ambivalente em que, ao mesmo tempo que agrega, também dissocia: "A pressão do geral dominante sobre todo o particular, sobre os indivíduos e as instituições individuais, tende a desintegrar o particular e o individual, assim como sua capacidade de resistência". Parece-me que é dessa ação desagregadora de resistência e identidade que dona Zabelê fala em sua narrativa da dispersão:

Antigamente só morava índio aqui, os brancos começaram a chegar depois, foram tirando os índios, comprando as terrinhas dos índios, porque os índios foram vendendo, foram saindo, outros foram morrendo, outros moram em Prado, só era índio, da ponte para cá, era puro índio que morava.

Tinha muito cajueiro, tudo fechadinho, só tinha aquela estradinha que passava, não tinha carro, tinha só as barraquinhas de índio como essas casinhas ali, de um lado e de outro da estrada, só tinha um trilho para passar, mas foram tirando os índios dali e tem uns que não querem mais ser índios, têm vergonha de ser índios, os índios daqui mesmo muitos perderam o costume por causa dos brancos, porque os brancos ficam fazendo pouco da gente" (Relato de Zabelê, em Rodrigues, Silva \& Soares, 2005, p.10).

O geral dominante impõe-se sobre o território Pataxó e em consequência sobre sua identidade. Torna-se interessante dizer que a instituição escolar colaborou fortemente para que os índios sentissem vergonha de suas práticas culturais e abrissem mão de si. No mesmo caderno, Esperança Luminosa, a menina Karine, da aldeia Cahy, deixa claro o desejo coletivo de uma escola indígena, assim como os motivos que o justificam:

Precisamos construir um colégio só para a gente, porque nós estudamos em um colégio de brancos, sofremos preconceito. É porque nós sofremos preconceito que pedimos um colégio, porque o pessoal da escola fica falando, fica fazendo piadinha, entende? A gente fica meio escabreado, e nossos colegas mangam muito da gente, dos índios, às vezes ficamos cantando nossas músicas, do nosso Toré que a gente dança, eles zombam da cara da gente e falam que Cumuruxatiba não é aldeia dos índios (Relato de Karine, em Rodrigues, Silva \& Soares, 2005, p.10).

Em seu breve relato, a garota reivindica o direito a uma escola indígena, no que é atendida em 2006 com a criação da Escola Estadual Indígena Diferenciada Intercultural Bilíngue Kijêtxawê Zabelê, cujo nome é uma homenagem à corajosa mulher-pássaro de Barra Velha.

Em linhas gerais, para Adorno (1995, p.112-120), o lugar ideal para o germinar de uma educação contra a barbárie seria a infância, etapa da vida ideal para o desenvolvimento de práticas educativas afetivas desprovidas de apego por excessos de disciplina, esforço e dureza. A escola seria então um espaço para a admissão da fraqueza, da dor, da mendicância e incompletude, capazes de nos levar ao encontro do 
outro. Porém, para o autor, isso não quer dizer uma pregação em favor da ordem cristã relativa ao amor, pois, para ele, "A recomendação do amor - tanto mais na forma imperativa, de que se deve amar - constitui em si mesma um componente da ideologia que eterniza a frieza. Dela fazem parte o caráter coercitivo, repressivo, que atua contra a capacidade de amar". Penso que essa educação contra a indiferença deva acontecer tanto no chão da escola indígena, quanto da não-indígena. Penso que, em nome disso, se deve também insistir na inclusão de narrativas indígenas, para além de produções românticas indianistas e lendas superficiais e estéreis, no cotidiano de leitura da escola pretensamente branca.

É possível ainda, ver na dialética da agregação - dissociação denunciada por Adorno (1995), um dispositivo eficiente para isolar os sujeitos. A característica básica desse isolamento é para Hanna Arendt (1967, p.526-527) "a impotência, na medida em que a força sempre surge quando os homens trabalham em conjunto, 'agindo em concerto (Burke)'; os homens isolados são impotentes por definição”. Para a filósofa, estar isolado é perder a capacidade de agir na esfera política, porque não há um outro com quem articular a ação. Porém, em situações de isolamento, permanecem as capacidades de sentir, pensar e inventar, enquanto que na solidão, experiência radical e desesperadora de não pertencer ao mundo, tais ações seriam impossíveis. Não arriscaria dizer que a diáspora provocada por sucessivas violências contra o povo Pataxó tenha culminado com a solidão de seus sujeitos, mas que certamente ocasionou, até o início do processo de retomada territorial em 2000, um isolamento político capaz de silenciar por décadas suas vozes, sua língua materna e suas identidades.

A partir da reflexão provocada por Arendt (1967), quero acrescentar aos motivos para narrar, a necessidade dos Pataxó de sair do isolamento e de ocupar cada vez mais espaços potencialmente políticos para sua luta para permanecer sendo povo indígena. Para isso, é preciso também que sejam pensados dispositivos de visibilidade suficientes e adequados para que a experiência seja partilhada, para que a tela entre o eu e o outro possa se romper. Nesse sentido, Jacques Ranciére (2010, p.150):

O problema não é opor a realidade às suas aparências. É sim, construir outras realidades, outras formas de senso comum, ou seja, outros dispositivos espaço-temporais, outras comunidades das palavras e das coisas, das formas e das significações.

\section{5) Considerações finais}

Para pensar a experiência como algo possível, penso ser interessante trazer Walter Benjamin, em O narrador (1994, p.197-198), quando este aborda as situações da modernidade que inviabilizariam a experiência por meio daquele que narra a dor. $\mathrm{O}$ escritor sugere que "tudo indica que continuarão caindo até que seu valor desapareça de tudo". Isso ocorreria pela mudez dos combatentes que voltavam da guerra; pela nulidade atual da ação de dar conselhos; pela extinção da sabedoria; pelo desaparecimento de uma comunidade de ouvintes. 
A despeito do que prevê Benjamin (1994), na comunidade indígena Pataxó do extremo sul baiano, não se esgotaram as condições apontadas por ele como fundamentais para a experiência mediada pela narração. Zabelê, assim como tantos anciãos da Barra do Cahy, sabe ainda narrar, mesmo que por um tempo tenha sido emudecida, tenha tido sua "faculdade de intercambiar experiências" interditada.

Além de seus narradores, o povo Pataxó, ao frustrar a proposta colonizadora do isolamento, reestabelece sua comunidade de ouvintes ávida de conselhos, aqui compreendidos como sugestões de continuação da história, como possibilidades de acender centelhas desde um passado, para os indígenas, temporalidade, materialmente e espiritualmente presentes para a construção de novas histórias. Para Benjamin (1994, p. 201) "O conselho tecido na substância viva da existência tem um nome: sabedoria - o lado épico da verdade”. Atestando essa afirmação, nas aldeias, quem pode contar é aquele que sabe, o sábio, o velho.

Nesse contexto, os ouvintes experimentam o fato contado pelos narradores - de coisas vivenciadas por eles ou contadas por outros antes deles - especialmente enquanto trabalham, enquanto tecem as fibras, dando formas a seus trajes típicos, fabricam o artesanato, a tinta para suas pinturas, enquanto trabalham a terra, fazem a farinha e o beiju; enfim, a condição ideal para Benjamin (1994, p.205), uma vez que "Quando o ritmo do trabalho se apodera dele, ele escuta as histórias de tal maneira que adquire espontaneamente o dom de narrá-las". Assim, o narrador não apenas partilha experiência, mas forma outros narradores, aqueles que impedirão o estancamento da história, não dessa de fatos em tese verdadeiros, mas dessa que permite a apropriação de uma reminiscência necessária para a resistência contra o isolamento e em última instância a solidão, lugar do desenraizamento, do ser humano como objeto descartável, supérfluo.

Assim, cabe aos narradores Pataxó partilhar suas experiências de dor, de algum modo, também nossas, assim como pensar dispositivos de visibilidade que façam emergir tanto no contexto das aldeias quanto no das cidades as narrativas da dor desenroladas no chão de nosso país. É preciso contar histórias de índios não alencarianos, mas sim desses que dançam o toré (mesmo que awê) de aparelhos ortodônticos e tênis Nike chineses, mas que reivindicam em nome de uma ancestralidade viva, latente e atual seu direito a um território imemorial e a uma identidade construída por um jeito próprio de ser e de estar no mundo.

Para continuar a luta intensificada no movimento "Brasil outros 500", em Porto Seguro, em abril de 2000, os Pataxó precisam continuar narrando, ainda que de forma artesanal, o massacre desencadeador da dispersão e da dor de ser errante e rejeitado em seu próprio berço-terra: o Fogo de 1951. Narrar sempre: hoje, através da mulher-pássaro Zabelê e do militante Edmundo Santos; amanhã, através de Karine, menina da aldeia Cahy. Narrar para que 1951 não mais se repita, para que esse povo não torne a ser camundu para nenhuma força representativa de um poder alheio. Narrar, mesmo na 
língua de quem promoveu o horror, para, quem sabe, depois narrar, confortavelmente, na língua-mãe, no patxohã, a linguagem dos guerreiros e guerreiras Pataxó.

\footnotetext{
i No tocante ao aspecto linguístico, em respeito ao que sugere a Convenção de 1953 da Associação Brasileira de Antropologia (ABA, o nome do povo indígena Pataxó não será pluralizado.

ii Ritual de música e dança realizado em momentos decisivos para o povo Pataxó (festa, reuniões, manifestações etc). Também chamado toré.

iii Globo rural. Índios fecham BR - $101 \mathrm{em}$ protesto contra a demarcação de terras. http://g1.globo.com/economia/agronegocios/vida-rural/noticia/2012/04/indios-fecham-br-101-emprotesto-por-agilidade-na-demarcacao-de-terra.html. Acesso em 07 de junho de 2012.
}

\section{Referências bibliográficas}

ADORNO, Theodor W. "Educação após Auschwitz". In: Palavras e Sinais: modelos críticos 2. Trad. Maria Helena Ruschel. Petrópolis: Vozes, 1995. pp.104-123.

AGAMBEN, Giorgio. “A testemunha”. In: O Que Resta de Auschwitz? Trad. Selvino J. Assman. São Paulo: Boitempo, 2008.

ARENDT, Hanna. "Ideologia e terror: uma nova forma de governo". In: Origens do Totalitarismo. Trad. Roberto Raposo. 7. ed. São Paulo: Companhia das letras, 1967. pp. 512-532.

BATISTA, Maria Geovanda. O Processo de Etnogênese dos Pataxó de Cumuruxatiba do Prado - BA publicado no site http://www.rededesaberes.org/3seminario/anais/textos. Acesso em 21 de Agosto de 2011.

BENJAMIN, Walter. "O narrador". In: Magia, Técnica, Arte e Política: ensaio sobre literatura e história da cultura. Trad. Sérgio Paulo Rouanet. 7. ed. São Paulo: Brasiliense, 1994. pp. 197-221.

Globo rural. Índios fecham BR - 101 em protesto contra a demarcação de terras. http://g1.globo.com/economia/agronegocios/vida-rural/noticia/2012/04/indios-fechambr-101-em-protesto-por-agilidade-na-demarcacao-de-terra.html. Acesso em 07 de junho de 2012.

GOMES, Mércio. Pataxó Lutam por Demarcar Suas Terras em Porto Seguro. http://merciogomes.blogspot.com.br/2008/08/patax-lutam-por-demarcar-suas-terrasem.html. Acesso em 07 de abril de 2013.

KEHL, Maria Rita. "O sexo, a morte, a mãe e o mal". In: NETROVSKI, Arthur \& SELIGMANN-SILVA, Márcio (org.). Catástrofe e Representação. São Paulo: Companhia das Letras, 2003. P. 137-148.

RANCIÉRE, Jacques. "A imagem intolerável”. In: O Espectador Emancipado. Trad. José Miranda Justo. Lisboa: Orfeu negro, 2010. P. 123-153.

RODRIGUES, Maria Regina, SILVA, Sandra Maria, SOARES, Raimunda (org.). Esperança Luminosa - histórias, contos e cantos pataxó. Brasília: Cimi, 2005.

SANTOS, Edmundo. Povo Pataxó. www.indiosonline.net/povo_pataxó/. Acesso em 20 de maio de 2012.

SONTAG, Susan. Diante da Dor dos Outros. Trad. Rubens Figueiredo. São Paulo: Companhia das Letras, 2003.

WIESEL, Elie. "Por que escrevo?" In: Nelson H. Vieira (org.). Construindo a Imagem do Judeu. Rio de Janeiro: Imago, 1994. P.23-29. 
Anexos

Textos do caderno "Esperança Luminosa” (2005) na íntegra:

\section{ALDEIA BARRA VELHA \\ História contada por Dona Zabelê}

Eu morava na aldeia da Barra Velha, tive minha família toda por lá, depois que teve uma revolta na Barra Velha eu saí de lá e não quis ir mais para lá, agora nós estamos morando em Cumuruxatiba.

Eu vou contar muita coisa sobre a revolta, a polícia pegou o meu pai, pisou em cima dele, eu estava vendo tudo, levou minha mãe e amarrou perto de meu pai para eles mostrarem onde é que estavam os índios que correram. Pegaram um índio e o fizeram de camundu (cavalo), botaram uma cangalha e um caçoá em cima do velho para mostrar onde é que estavam os índios, mas como é que eles iam mostrar sem saber.

Todos os índios correram, foram embora para os matos e ficaram só os mais velhos que não podiam correr e eles pegaram.

É por isso que eu não tenho coração de ir morar na Barra Velha, eu não, quando eu chego lá só me lembro disso, do que fizeram com o meu velho, aí não dá vontade mais de ficar lá, por isso vim embora pra Cumuruxatiba. Fiquei morando neste lugar até hoje.

Aqui tinha muito índio, todo mundo tinha amizade comigo, aqui também era uma aldeia, e eu disse:

- Agora aqui é uma aldeia, então eu fico aqui, e para lá não vou mais, lá não tem meu pai, não tem minha mãe, só tenho um irmão, mas não me dá vontade de ir mais lá.

Depois chegou o tempo de Rosarinha que perguntou se eu queria ir para a Barra Velha ou queria ficar aqui em Cumuruxatiba, eu disse para Rosarinha que queria ficar aqui, porque para lá eu não queria ir mais. E ela disse que estava bom, depois disso ela foi embora. Passou uns tempos, Rosarinha chegou de novo fazendo a mesma pergunta e eu falei a mesma coisa.

Depois chegou um homem e falou assim: - Vocês vão sair daqui porque aqui não é de vocês, isso aqui é meu porque eu já comprei.

O nome desse homem é Expedito, foi ele que tirou nós da roça, ele é um branco que não era daqui. Nós viemos para a rua e ficamos morando na Vila. Esse Expedito sumiu, nunca mais apareceu, foi só para tirar nós da roça e ficar passando fome aqui na rua. Em casa não tinha nada e ficou nossa roça para lá, e aqui nós estamos até hoje.

Eu sinto quando meus irmãos chegam aqui e eu não tenho nada para dar, nós não temos nada, o branco não deixa fazer nada.

Antigamente só morava índio aqui, os brancos começaram a chegar depois, foram tirando os índios, comprando as terrinhas dos índios, porque os índios foram vendendo, foram saindo, outros foram morrendo, outros moram em Prado, só era índio, da ponte para cá era puro índio que morava.

Tinha muito cajueiro, tudo fechadinho, só tinha aquela estradinha que passava, não tinha carro, tinha só as barraquinhas de índio como essas casinhas ali, de um lado e de outro da estrada, só tinha um trilho para passar, mas foram tirando os índios, os brancos foram chegando, de repente foram diminuindo os índios, os índios daqui mesmo, muitos perderam os costumes, perderam o costume por causa dos brancos, porque os brancos ficam fazendo pouco da gente, quem quiser falar de mim que fale, eu 
nasci e sou índia até eu morrer, com certeza, pois eu sinto maior orgulho de ser índia, e estou morando aqui.

Agora que meus parentes chegaram eu sinto mais prazer ainda deles chegarem para me visitar, porque com fé em Deus nós vamos para frente.

\section{KARINE}

\section{Jovem Pataxó da Aldeia Cahy}

Meu nome é Karine. Eu vou falar sobre os índios que sofreram a invasão pelos pistoleiros lá na Barra do Cahy e também quero falar como esses índios estão vivendo hoje.

Nós estamos sem terra para plantar, para trabalhar, para poder termos nossos próprios alimentos, nós estamos sem atendimento médico com frequência, e também dizer que nós estamos precisando de dentistas para as crianças e para a gente também, porque muitas aldeias por aí já têm, e a nossa ainda não. A nossa aqui ainda nós não conseguimos.

Precisamos construir um colégio só para a gente, porque nós estudamos em um colégio de brancos, sofremos preconceito. É porque sofremos muito preconceito que pedimos um colégio, porque o pessoal da escola fica falando, fica fazendo piadinha, entende? A gente fica meio escabreado, e nossos colegas mangam muito da gente, dos índios, às vezes ficamos cantando nossas músicas lá para as pessoas e os nossos colegas começam a mangar da gente, das nossas músicas, do nosso Toré que a gente dança, eles zombam da cara da gente e falam que Cumuruxatiba não é aldeia dos índios.

Canto utilizado no awê:

\section{MÚSICA DE ZABELÊ}

Xororó canta na mata, sabiá na laranjeira

Xororó canta na mata, sabiá na laranjeira

Oi canta, canta Zabelê na subida da ladeira

Oi canta, canta Zabelê na subida da ladeira

Lá de cima da ladeira eu avistei a natureza

Lá de cima da ladeira eu avistei a natureza

Oi canta, canta Pataxó em louvor à natureza

Oi canta, canta Pataxó em louvor à natureza

Xororó canta na mata, sabiá na laranjeira

Xororó canta na mata, sabiá na laranjeira

Oi canta, canta Zabelê na subida da ladeira

Oi canta, canta Zabelê na subida da ladeira

Lá de cima da ladeira eu avistei a natureza

Lá de cima da ladeira eu avistei a natureza

Oi canta, canta Pataxó em louvor à natureza

Oi canta, canta Pataxó em louvor à natureza

Lá de trás daquele monte tem um pé de girassol

Lá de trás daquele monte tem um pé de girassol

E nele está escrito a terra dos Pataxó

E nele está escrito a terra dos Pataxó 